\title{
Análise Televisual Convergente: um procedimento metodológico para leitura crítica dos processos comunicativos de telejornais e programas televisivos
}

\author{
Beatriz Becker \\ https://orcid.org/0000-0001-6665-8911 \\ I- UFRJ \\ Rio de Janeiro (RJ), Brasil
}

Resumo: A partir de um mapeamento de metodologias empregadas em estudos acadêmicos sobre telejornalismo produzidos entre 2015 e 2017 em 11 bancos de dados, este artigo sugere a relevância do olhar sobre as imagens e suas combinações com palavras na produção de sentidos. O trabalho também propõe o reconhecimento da necessidade de articular às análises textuais de telejornais e programas televisivos quatro instâncias que configuram os processos comunicativos no ambiente convergente: singularidades da ambiência, circulação, características de organizações e de práticas produtivas e interações das audiências. Nesse sentido, apresenta o esquema analítico da Análise Televisual Convergente (ATC), um procedimento metodológico possível para a leitura crítica dos textos audiovisuais nas pesquisas em comunicação e em processos de aprendizagem num momento de transformação da produção e consumo de conteúdos e formatos em áudio e vídeo decorrente da digitalização dos meios.

Palavras-Chave: telejornalismo; programas televisivos; Análise Televisual Convergente; processos de aprendizagem.

Abstract - Convergent Televisual Analysis: a methodological procedure for the critical reading of the communicative processes of TV News and television programs. From a mapping of methodologies employed in academic studies about television journalism, produced between 2015 and 2017 in 11 databases, this article suggests the relevance of looking over the images and their combinations with words in the production of meanings. It also proposes the recognition of the necessity to articulate to the textual analyses of TV News and television programs four instances that constitute the communicative processes in the 
convergent environment: singularities of ambience, circulation, features of organizations and productive practices and interactions of audiences. In this sense, this paper presents the analytic framework of the Convergent Televisual Analysis (ATC), a methodological procedure for the critical reading of audiovisual texts in communication research and learning processes at a time of transformation of production and consumption of audio and video contents and formats resulting from media digitalization.

Keywords: television journalism; television programs; Convergent Televisual Analysis; learning processes.

\section{Introdução}

No século XXI, a Comunicação se inscreve como área relevante do conhecimento científico para a compreensão das mudanças sociotécnicas (MARINHO; MARIÑO, 2018), mas também deve ser compreendida como um conjunto de investigações capazes de contribuir para a transformação social, ultrapassar o paradigma cognitivo hegemônico e se constituir em uma ciência redescritiva no interior do bios midiático (SODRÉ, 2014). Para além do estudo das intencionalidades da produção midiática, a Comunicação deve viabilizar o entendimento de conversações e controvérsias socioculturais ou de práticas cotidianas de resistência e de resiliência coletivas. Torna-se relevante observar as subjetivações provocadoras de fissuras nas ordenações de forças dominantes diante da complexificação dos processos de comunicação midiáticos na contemporaneidade, os quais instigam reflexões sobre fundamentos epistemológicos e metodológicos capazes de auxiliar a compreensão das lógicas das mídias e das práticas socioculturais que emergem de seus usos e apropriações, dos circuitos comunicativos e das interações que se estabelecem no ambiente convergente (ALZAMORA; ZILLER; D’ANDRÉA, 2018; MARTINO, 2018; BRAGA, 2017). Na realização da pesquisa todo conhecimento do social é um recorte ou uma aproximação da realidade, mas as metodologias empregadas podem auxiliar a "tradução" de maneiras do pensar e sentir de instituições e da cultura de comunidades distintas e das articulações entre o individual e o coletivo (MINAYO, 2014).

Na década de 1970, Williams (2016) já se recusava a entender a televisão sob o viés do determinismo tecnológico e como uma força que age por si mesma com propriedades fixadas do meio. Ele abriu uma percepção da TV como tecnologia e forma cultural, que converge tanto formas derivadas de outros tipos de atividades culturais quanto inovadoras, e sinalizou que a análise de TV não deve ser reduzida ao seu controle ou a efeitos homogêneos, uma vez que há aqueles que são previstos e outros não. O pesquisador sugeriu que a televisão não é estruturada por unidades separadas nem dividida entre programas e anúncios publicitários, mas por um "fluxo planejado" da radiodifusão que influencia as formas textuais que veicula. Na medida em que a televisão se expande em outras plataformas que também influenciam as formas textuais que abrigam na atualidade, a noção de fluxo de Williams foi superada. Hoje, a própria Comunicação pode ser vista 
como um fluxo incessante de ideias, informações e expectativas que circulam em formas e reconfigurações sucessivas (BRAGA, 2017). A singular abordagem da televisão como experiência cultural de Raymond Williams, entretanto, não se dissolveu e a análise dos programas televisivos (MACHADO, 2003) ainda oferece respostas. Contudo, é necessário descentrar a ênfase no produto e articulá-lo às singularidades da ambiência, à sua circulação, às características das organizações e das práticas produtivas e às interações das audiências, em um momento em que a produção e o consumo de conteúdos audiovisuais se tornam mais diversos e acelerados. A partir de um mapeamento de metodologias empregadas em pesquisas acadêmicas sobre telejornalismo de 2015 a 2017 em 11 bases de dados, este trabalho reflete sobre a necessidade de métodos mais abrangentes para a análise de telejornais e de programas televisivos no ambiente convergente, decorrentes da digitalização dos meios, discute a relevância do estudo das imagens no texto audiovisual e apresenta o procedimento da Análise Televisual Convergente (ATC).

Os telejornais tendem a ser considerados produtos arcaicos da indústria massiva do século XX que reduzem a complexidade dos jogos políticos e dos arranjos econômicos e favorecem grupos dominantes. De fato, os telejornais enquadram a realidade, por meio de estratégias discursivas que valorizam a sua própria mediação, se oferecem como lugares de reconhecimento da(s) verdade(s) referente(s) à vida social do país e exercem expressiva influência na compreensão da experiência cotidiana. No entanto, o telejornalismo não é um gênero ${ }^{1}$ televisivo anacrônico na cultura digital, se reinventa no ambiente convergente, caracterizado pela coexistência de antigos e novos modelos de produção e consumo de conteúdos e formatos audiovisuais noticiosos, e permite aos cidadãos ter acesso e compartilhar informações, sobretudo nas transmissões ao vivo de acontecimentos de grande repercussão (BECKER, 2016). Hoje, a população brasileira ainda assiste mais à programação da televisão em tempo real do que pela internet. Os telejornais são a principal fonte de informação para a maioria dos brasileiros, concentram grande parte do conteúdo das emissoras de televisão aberta no Brasil e reúnem expressivos investimentos financeiros. No entanto, o telejornalismo está desafiado a encorajar o engajamento do público, tornando a experiência de ver os telejornais mais participativa (BECKER, 2018). Os modos como os telejornais se expandem em múltiplas plataformas e as maneiras que as audiências interagem com os noticiários, por meio de dispositivos móveis e nas redes sociais, afetam as leituras dos acontecimentos em diferentes contextos, transformam o papel social do telejornalismo e as práticas produtivas e demandam novas abordagens teórico-metodológicas para a análise desses processos comunicativos. O esquema analítico aqui apresentado busca ampliar o escopo da metodologia da Análise Televisual (AT) anteriormente sistematizada (BECKER, 2012; 2016), a qual tem sido utilizada por pesquisadores de diferentes níveis de formação na Graduação e na Pós-Graduação,

1 Os gêneros televisivos aqui são compreendidos como categorias culturais que organizam as práticas televisivas e como estratégias de comunicação com o espectador em contextos específicos (MITTEL, 2004). 
auxiliando o entendimento da complexidade dos códigos audiovisuais na elaboração e ressignificação dos sentidos dos discursos midiáticos de obras televisivas ficcionais e não ficcionais ${ }^{2}$. Esta metodologia revisitada ganha aqui um sobrenome, e é nomeada de Análise Televisual Convergente, agregando à AT um procedimento metodológico possível para ler relações entre imagens, palavras, dispositivos ${ }^{3}$, pessoas e práticas produtivas no território virtual e ser utilizada como ferramenta para leitura crítica dos telejornais e de outras obras televisivas em pesquisas de comunicação e em processos de aprendizagem institucionais e informais. Afinal, o olhar não se opõe ao agir e a posição do espectador (ou do aluno) não deve ser reduzida à passividade e à contemplação (RANCIÈRE, 2017), pois corresponde a um conjunto de traduções de textos e materialidades distintas capazes de deslocar percepções e posições sem desconsiderar as complexas relações entre palavras e imagens.

\section{Leitura de Imagens}

Ao invés de se pensar as imagens apenas como instrumentos de poder que tornam inseparáveis o real e a aparência, projeções da ideologia ou tecnologias de dominação, destacando as suas potências maléficas, Mitchell (2017) sugere observar o campo social do visual, considerando que os processos cotidianos de olhar e ser olhado constituem um complexo campo de reciprocidade visual. Mesmo ao interagir com imagens digitais, que são constituídas por números e códigos planejados, não carregam vestígios do mundo social e histórico e indicam um novo regime do visível, os sujeitos e seus agenciamentos podem, por meio da interpretação, inverter ou desviar percursos prescritos tanto de formasimagens representadas quanto de programas televisivos (GUIMARÃES, 2002). Existem diferentes possibilidades de leitura das imagens mediante o uso de métodos distintos, mas as pesquisas em comunicação tendem a focalizar as imagens técnicas, ou seja, imagens que sofrem a mediação e/ou a intervenção de um aparato técnico (MARTINO, 2018). Entretanto, os estudos das narrativas audiovisuais na atualidade não se debruçam sobre uma imagem particular, procuram entender como esta é constituída em um período histórico e em um contexto cultural específicos, o lugar onde circula como representação ${ }^{4}$ e reflete significações. Estudar a representação imagética demanda, portanto, compreender

2 Este percurso metodológico é formado por três etapas: a Descrição ou Contextualização, destacando determinantes político-econômicos e socioculturais do objeto de estudo e da organização produtiva onde este está inserido, a Análise Televisual propriamente dita, formada por um estudo quantitativo e qualitativo do texto em áudio e vídeo, e a interpretação dos resultados. Seis categorias (Estrutura Narrativa, Temática, Enunciadores, Visualidade, Som e Edição) e três princípios de enunciação (Fragmentação, Dramatização e Definição de Identidades e Valores) são aplicados na segunda etapa da análise televisual (BECKER, 2016).

3 O dispositivo é entendido como um regime ou quadro organizador inscrito em jogos de poder que também o condicionam e que funciona como um lócus ou ambiência que gera relações e adapta-se às tentativas interacionais que abriga (ALZAMORA; ZILLER; D`ANDRÉA, 2018).

4 A representação é uma das práticas centrais que produz a cultura, parte do processo pelo qual os significados, mapas conceituais, códigos ou sistemas de linguagem são produzidos, compartilhados e estruturam o olhar. Porém, as suas significações dependem da interpretação. A estabilização de um sentido por convenções sociais não é absoluta, um regime de representação pode ser transformado e tanto o "senso comum" quanto o "bom senso" podem revelar as suas naturezas contraditórias (HALL, 2011; MINAYO, 2014). 
a política da representação, como as imagens atribuem valores a determinados grupos sociais e como as narrativas transmitem significados (BELTRÁN, 2018). Rancière (2016) explica que a politicidade das imagens deve ser encontrada em um regime determinado de articulações que definem os seus sentidos e as suas funções na esfera social, o que ele chama de regime de imagéité ou regime de imaginidade. Para o pesquisador francês, a representação "não é o ato de produzir uma forma visível; é o ato de dar um equivalente, coisa que a palavra faz tanto quanto a fotografia" (RANCIÈRE, 2017, p. 92), ou seja, "é um jogo complexo de relações com o visível e o invisível, o visível e a palavra, o dito e o não dito" (ibidem). Ele argumenta que a crítica do espetáculo identificou a imagem com a denúncia platônica do engodo das aparências e da passividade do espectador, e que as imagens vivem em uma atmosfera de julgamento. Porém, para o autor, o sistema de informação não funciona pelo excesso de imagens, mas pelo modo como seleciona seres que falam, fazendo do verbal o privilégio de poucos e do visual o território permitido às multidões. Nem toda imagem seria alienante e as palavras também são formas de redistribuição dos elementos da representação. A imagem não é uma exclusividade do visível, há um visível que não produz imagem e imagens que estão todas em palavras. Segundo Rancière (2016), as imagens são relações entre uma visibilidade e uma potência de significação e de afeto que lhes é associada e as preenche; e as maneiras como nos afetam nem sempre são evidentes ou previsíveis. Afinal, tanto as imagens quanto as palavras usadas para asseverar a verdade também podem ser usadas para enganar (SANTAELLA; NÖTH, 2008). Cabe ao analista decifrar um regime particular de articulação entre o visível e o dizível e a análise do texto audiovisual não deve prescindir da leitura crítica da visualidade como recurso de construção de sentido, como permite a aplicação da AT, desvelando o regime de 'imaginidade', a política de representação e/ou o jogo de contar histórias factuais e/ou ficcionais escritas com imagens e palavras. Os textos audiovisuais não são apenas meios de reprodução de valores e estéticas dominantes; são também práticas socioculturais constituídas por sistemas mais ou menos inventivos de representações e combinações entre som e imagem que não têm um sentido fixo (BECKER, 2016). Porém, se a partir do mito platônico das cavernas e durante séculos a imagem foi identificada como aparência e compreendida como um instrumento de manipulação, de persuasão religiosa ou política, estas assunções e premissas ainda influenciam pesquisas que privilegiam a interpretação dos arranjos verbais no estudo das significações do texto audiovisual, como identificado no mapeamento dos métodos utilizados em estudos recentes de telejornalismo.

\section{Mapeamento de metodologias aplicadas em estudos de telejornalismo}

Inspirando-se no percurso metodológico proposto anteriormente (BECKER, 2015), foram coletados no mês de junho de 2018 os resumos publicados entre 2015 e 2017 de todas as Dissertações e Teses de Doutorado sobre telejornalismo catalogadas pela Coordenação 
de Aperfeiçoamento de Pessoal de Nível Superior, a CAPES ${ }^{5}$, dos artigos publicados nas sete revistas científicas brasileiras A2 da área de avaliação Comunicação e Informação, identificadas no Qualis Periódico disponível na plataforma Sucupira ${ }^{6}$, e de todos os trabalhos apresentados nos congressos ${ }^{7}$ da Associação Nacional dos Programas de Pós-Graduação em Comunicação (Compós), da Associação Nacional dos Pesquisadores em Jornalismo (SBPJor) e da Sociedade Brasileira de Estudos Interdisciplinares da Comunicação (Intercom) ${ }^{8}$. Posteriormente, foram realizadas a leitura dos resumos e a interpretação dos resultados.

\begin{tabular}{|c|c|c|}
\hline $\begin{array}{c}\text { Mapeamento dos } \\
\text { Trabalhos sobre } \\
\text { Telejornalismo 2015-2017 }\end{array}$ & Número de Trabalhos & Metodologias Aplicadas \\
\hline $\begin{array}{l}\text { CAPES } \\
\text { Foram utilizados na } \\
\text { busca a palavra-chave } \\
\text { "telejornalismo" e os } \\
\text { filtros da grande área de } \\
\text { conhecimento (Ciências } \\
\text { Sociais Aplicadas) e da } \\
\text { área de conhecimento } \\
\text { (Comunicação). Os trabalhos } \\
\text { produzidos em 2017 não } \\
\text { estavam disponíveis no } \\
\text { período da coleta. }\end{array}$ & $\begin{array}{l}\text { Foram produzidos } 57 \\
\text { trabalhos sobre telejornalismo } \\
\text { em } 2015 \text { e em } 2016,47 \\
\text { dissertações de mestrado } \\
\text { e } 10 \text { Teses de doutorado. } \\
\text { Mas a amostra deste } \\
\text { mapeamento foi formada por } \\
44 \text { Dissertações e } 8 \text { Teses, } \\
\text { uma vez que três trabalhos de } \\
\text { Mestrado e um de Doutorado } \\
\text { não estavam relacionados a } \\
\text { pesquisas sobre esta temática } \\
\text { e o link de uma Tese levava a } \\
\text { outra investigação. }\end{array}$ & $\begin{array}{l}\text { Nem todas as pesquisas explicitam o percurso } \\
\text { metodológico adotado nos resumos dos trabalhos. } \\
\text { As metodologias referidas foram muito variadas } \\
\text { e somaram } 17 \text { métodos diferentes de análise nas } \\
\text { dissertações: Análise Televisual; Análise de Conteúdo; } \\
\text { Análise Qualitativa; Modos de Endereçamento; } \\
\text { Observação Participativa; Análise Comparativa; } \\
\text { Análise Textual; Análise baseada em teorias e } \\
\text { conceitos cinematográficos; Análise Crítica da } \\
\text { Narrativa; Metodologia Interpretativa; Método Diana } \\
\text { Rose; Protocolo analítico de Circuito Cultural; } \\
\text { Estudo de Caso; Entrevistas; Enquadramento; Estudo } \\
\text { de recepção e Análise de Percepção Auditiva. A } \\
\text { metodologia mais utilizada em cinco desses trabalhos } \\
\text { foi a Análise de Conteúdo. Nas teses de doutorado } \\
\text { o método mais aplicado foi a Análise do Discurso } \\
\text { em duas das oito pesquisas. Outras três metodologias } \\
\text { foram: Análise Qualitativa das interações entre } \\
\text { produção e recepção em uma rede social; análise } \\
\text { de regimes imagéticos de materialidades fotográficas } \\
\text { e categorização do objeto de estudo eleito. Em um } \\
\text { dos trabalhos foram usados quatro procedimentos } \\
\text { em conjunto: Revisão Bibliográfica, Observação e } \\
\text { Monitoramento; Análise Qualitativa e Entrevistas. } \\
\text { Duas investigações se debruçaram sobre a concepção } \\
\text { de um modelo de análise do telejornal. }\end{array}$ \\
\hline $\begin{array}{l}\text { Revistas Científicas A2 } \\
\text { Os artigos foram } \\
\text { identificados por meio de } \\
\text { uma análise dos Sumários } \\
\text { de cada uma das edições } \\
\text { estudadas. }\end{array}$ & $\begin{array}{l}\text { Entre } 2015 \text { e } 2017 \text { foram } \\
\text { publicados } 739 \text { artigos } \\
\text { científicos nestas revistas, } \\
\text { mas apenas oito trabalhos } \\
\text { sobre telejornalismo. O } \\
\text { percurso metodológico é } \\
\text { indicado com clareza em } \\
\text { quatro dos oito trabalhos. }\end{array}$ & $\begin{array}{l}\text { Apenas três artigos focalizaram a análise do texto } \\
\text { audiovisual e somente dois textos se dedicaram } \\
\text { à formulação ou a metodologias de análise das } \\
\text { narrativas jornalísticas audiovisuais. }\end{array}$ \\
\hline
\end{tabular}

Tab. 1. Síntese do mapeamento de metodologias aplicadas em estudos de telejornalismo (2015-2017).

Fonte: da autora (2018).

5 Disponível em: <http://catalogodeteses.capes.gov.br/catalogo-teses/\#!/>. Acesso em: 10 jun. 2018.

6 Os periódicos observados foram: Matrizes (USP); Galáxia (PUC-SP); Famecos (PUC-RS); E-Compós (Compós); Revista Brasileira de Ciências da Comunicação (Intercom); Comunicação, Mídia e Consumo (ESPM-SP) e Em Questão (UFRGS).

7 Disponível em: <http://www.compos.org.br/anais.php>; <http://sbpjor.org.br/sbpjor/>; <http://www. portalintercom.org.br/eventos1/congresso-nacional/apresentacao5>. Acesso em: 15 jun. 2018.

8 Agradeço a colaboração do ex-bolsista PIBIC e jornalista, João Paulo Saconi Michael, pelo levantamento dos dados quantitativos desse mapeamento. 


\begin{tabular}{|c|c|c|}
\hline $\begin{array}{c}\text { Mapeamento dos } \\
\text { Trabalhos sobre } \\
\text { Telejornalismo 2015-2017 }\end{array}$ & Número de Trabalhos & Metodologias Aplicadas \\
\hline $\begin{array}{l}\text { Compós } \\
\text { Os textos foram encontrados } \\
\text { nos Anais do site da } \\
\text { Compós, organizados } \\
\text { nos diferentes Grupos de } \\
\text { Trabalho existentes. }\end{array}$ & $\begin{array}{l}\text { Em 2015, } 2016 \text { e 2017, foi } \\
\text { registrada a produção de } 60 \\
\text { trabalhos acadêmicos nos } \\
\text { GTs Estudo de Jornalismo } \\
\text { e Estudos de Televisão da } \\
\text { Compós. }\end{array}$ & $\begin{array}{l}\text { Seis trabalhos apresentados em ambos os GTs } \\
\text { refletiram sobre o telejornalismo. Dois textos } \\
\text { propuseram esquemas analíticos do jornalismo } \\
\text { televisivo, amparados na Semiótica e na Análise } \\
\text { do Discurso e o outro em pesquisa bibliográfica e } \\
\text { entrevistas. As metodologias utilizadas nos demais } \\
\text { artigos foram Observação Etnográfica, Análise } \\
\text { Textual e estudo de enquadramento. }\end{array}$ \\
\hline $\begin{array}{l}\text { SBPJor } \\
\text { Os artigos foram } \\
\text { identificados nos Anais } \\
\text { dos Encontros de } 2015 \text { e } \\
2016 \text { no portal da SBPJor } \\
\text { com a palavra-chave } \\
\text { "telejornalismo". Os Anais } \\
\text { de } 2017 \text { não estavam } \\
\text { disponíveis quando a coleta } \\
\text { foi realizada. }\end{array}$ & $\begin{array}{l}\text { Nos Encontros Nacionais } \\
\text { dos dois anos verificou- } \\
\text { se a produção de } 38 \\
\text { trabalhos acadêmicos sobre } \\
\text { telejornalismo. }\end{array}$ & $\begin{array}{l}\text { Dos } 38 \text { trabalhos apresentados, } 20 \text { corresponderam } \\
\text { a reflexões críticas ou não explicitaram o percurso } \\
\text { metodológico. Entre os } 18 \text { trabalhos que fizeram } \\
\text { referência às metodologias adotadas, as mais } \\
\text { citadas foram a Análise de Conteúdo e a Análise do } \\
\text { Discurso. Dois trabalhos estabeleceram diálogos } \\
\text { com referenciais teórico-metodológicos de estudos } \\
\text { de telejornalismo e três artigos esboçaram uma } \\
\text { metodologia para a análise de telejornais. Os } \\
\text { métodos explicitados nos demais textos remeteram } \\
\text { a relações interdisciplinares entre a Comunicação, o } \\
\text { Jornalismo e outros saberes. }\end{array}$ \\
\hline $\begin{array}{l}\text { Intercom } \\
47 \text { publicações foram } \\
\text { identificadas nos Anais } \\
\text { da Intercom, filtradas por } \\
\text { meio da palavra-chave } \\
\text { "telejornalismo" em } \\
\text { 2015. Os artigos foram } \\
\text { encontrados nos Grupos } \\
\text { de Telejornalismo e de } \\
\text { Televisão e Televisualidade } \\
\text { em } 2016 \text { e } 2017\end{array}$ & $\begin{array}{l}\text { Entre } 2015 \text { e } 2017 \text {, foi } \\
\text { registrada a produção de } 121 \\
\text { trabalhos acadêmicos sobre } \\
\text { telejornalismo na Intercom. } \\
\text { Não foi possível ter acesso ao } \\
\text { resumo de um dos trabalhos } \\
\text { e a amostra foi constituída, } \\
\text { portanto, por } 120 \text { trabalhos. }\end{array}$ & $\begin{array}{l}\text { As metodologias não foram citadas em } 55 \text { resumos } \\
\text { e } 51 \text { indicaram diálogos com outros campos de } \\
\text { conhecimento. A Análise de Conteúdo foi a mais } \\
\text { citada em } 14 \text { resumos. A revisão bibliográfica foi } \\
\text { referida em seis trabalhos, seguida da realização } \\
\text { de entrevistas. Em quatro trabalhos foi adotada a } \\
\text { Análise de Discurso e em outros quatro a Análise } \\
\text { de Enquadramento. Identificou-se um conjunto } \\
\text { de } 14 \text { artigos com esboços de modelos analíticos } \\
\text { amparados em estudos de telejornalismo. A maioria } \\
\text { dessas análises foi construída com aportes teóricos } \\
\text { de campos distintos, com predominância da Análise } \\
\text { de Conteúdo. Mas há um referencial teórico que se } \\
\text { fortalece nessas pesquisas. }\end{array}$ \\
\hline
\end{tabular}

Tab. 1 (cont.). Síntese do mapeamento de metodologias aplicadas em estudos de telejornalismo (2015-2017).

Fonte: da autora (2018).

Este mapeamento evidencia um processo de consolidação dos estudos de telejornalismo (EMERIN; COUTINHO; FINGER, 2018), porém, demonstra que as metodologias empregadas não são comumente indicadas nos trabalhos publicados nas revistas científicas e apresentados em congressos nacionais e que a elaboração de métodos para análise dos telejornais tampouco é privilegiada como objeto de estudo. Os percursos metodológicos referidos das pesquisas em telejornalismo são muito variados e estabelecem interlocuções com outros campos de saber. A Análise de Conteúdo é a dimensão teórico-metodológica mais citada neste estudo, ratificando resultados de pesquisa anterior (BECKER, 2015). Entretanto, ainda que não se manifeste um empenho significativo no estabelecimento de diálogos com metodologias já desenvolvidas nos estudos de telejornalismo, identifica-se a emergência de trabalhos que buscam explorar modelos analíticos, tomando a imagem e a visualidade como elementos relevantes de produção de sentidos dos telejornais. A intenção de transcender a tradicional dimensão verbal no estudo da organização narrativa do texto televisivo jornalístico já era anunciada em 
um dos pioneiros estudos de telejornalismo originário da metodologia da Análise Televisual. Contudo, a maioria das propostas metodológicas dos estudos de telejornalismo ainda privilegia o conteúdo em detrimento da forma e verifica-se uma carência de olhares sobre as combinações de imagens e palavras produtoras de sentidos constituídas na escrita e na leitura, bem como sobre o sistema comunicativo onde o texto está inscrito, as práticas produtivas e as interações das audiências. Assim, revela-se a necessidade de estudar os sentidos das imagens associadas aos demais códigos audiovisuais e utilizar métodos capazes de abordar de maneira mais abrangente os processos comunicativos nas análises dos telejornais e de programas televisivos. Afinal, o texto não é simplesmente um produto, resulta de práticas discursivas historicamente situadas em contextos culturais específicos, ganha sentidos no trabalho interpretativo e estes não se manifestam, necessariamente, "na circulação da informação, mas no compartilhamento de sensações, sentimentos, afetos e/ou mesmo na própria condição de estarmos juntos" (LEAL, 2018, p. 27). Buscando agregar à compreensão dos sentidos dos textos as lógicas das mídias e as práticas comunicativas no ambiente convergente que também influenciam as suas significações, a Análise Televisual Convergente (ATC) se constitui como um procedimento metodológico possível para a leitura dos telejornais e de programas televisivos e articula à AT quatro instâncias: as singularidades da ambiência e/ou dos dispositivos, as características das organizações e práticas produtivas, a circulação de um programa no ambiente convergente e as interações das audiências.

\section{Análise Televisual Convergente: um esquema analítico flexível para o estudo dos telejornais e de programas televisivos}

Nos estudos de televisão, o conceito de audiência ativa responde a inquietações referentes aos seus agenciamentos na decodificação dos textos e nas suas formas de interpretação. Entretanto, as audiências são distintas e suas relações com as mídias se manifestam de diferentes maneiras. Hills (2018) sugere que o termo "audiências difusas", cunhado por Nicholas Abercrombie e Brian Longhurst, relacionado tanto à transmissão broadcast quanto à cultura on demand, seria o mais adequado para nomear as maneiras como as pessoas agem assistindo à TV ou utilizando mídias móveis para consumir e compartilhar conteúdos e formatos audiovisuais, deslocando o foco na estrutura e no poder da mídia. Fausto Neto (2017), por sua vez, ressalta que na sociedade em midiatização, caracterizada pela centralidade das práticas midiáticas, as interações das audiências são mediadas por estratégias de contato que as induzem a se instalar em ambiências midiáticas, seguindo "operações pelas quais se destacam como coenunciadores de um trabalho tecno-simbólico que já não estaria apenas sob controle unilateral dos nichos institucionais de produção de mensagens" (FAUSTO NETO, 2017, p. 263). As regras dominantes dos jogos interacionais continuam a ser definidas pelos sistemas institucionais de produção e 
as audiências são projetadas em uma determinada cena na ambiência midiática, por meio de práticas discursivas. Porém, as atividades destes atores sociais oscilam entre atitudes contemplativas ou de apropriação e a produção não tem controle absoluto sobre o script de suas performances, o que também indica a necessidade de focalizar as dinâmicas da recepção na contemporaneidade ${ }^{9}$. As novas possibilidades de acesso e manejo das tecnologias de comunicação, entretanto, tornam a observação dos agenciamentos das audiências cada vez mais complexa e, segundo Braga (2017), um dos maiores desafios dos pesquisadores é apreender a circulação do produto após a recepção, uma vez que novos produtos são derivados dos primeiros (idem). Para o pesquisador, o círculo do produto é mais amplo que a relação que se estabelece da emissão à recepção e as conexões entre diferentes dispositivos interacionais se caracterizam como um circuito, que direciona o fluxo comunicacional em determinados contextos. Assim, como os receptores são ativos, "a circulação passa a ser vista como o espaço do reconhecimento e dos desvios produzidos pela apropriação" (BRAGA, 2017 p. 50) e podem emergir vozes que se posicionam de maneira crítica à mídia. Nesse fluxo, segundo o autor, o produto ocupa um lugar especial por sua materialidade e consequente facilidade de captura para observação e inferências (ibidem), moldando e sendo moldado pelos ambientes em que se põe a circular, sob tensionamentos de outros campos sociais e práticas socioculturais. Partindo da análise do produto televisual, sugere-se então, como propõe Braga (2017), questionar como o telejornal e os programas televisivos de gêneros distintos ocupam um lugar e atuam nesse circuito, uma vez que até mesmo os processos de transmidiação emergem de relações entre um texto de referência e um conjunto de outros textos que em torno dele se organizam a partir de estratégias da produção, ainda que a cultura participativa possa fazer emergir uma variedade de conteúdos que escapam às instruções dos produtores (FECHINE, 2018). O texto de referência também se constitui como ponto de partida para os estudos sobre o estilo televisivo, que oferecem possibilidades de entender o programa isoladamente, tecer especulações sobre a cultura na qual ele está inserido e examinar as atividades dos realizadores (ROCHA, 2016).

Contudo, nos estudos dos modos de produção televisivos, a ênfase das pesquisas sobre circulação recai sobretudo na distribuição e disseminação de conteúdos audiovisuais para entender as atuais transformações da experiência de consumo de imagens em movimento, decorrentes da portabilidade e da variabilidade de formas de acesso

9 Nos estudos de televisão as atividades interativas das audiências no ambiente convergente são abordadas em pesquisas sobre Social TV, que torna a experiência pessoal de assistir TV uma atividade de grupo social e até mesmo global. Nessas investigações são observados os modos como os fãs remixam conteúdos e atuam como curadores nas redes sociais e consideradas as estratégias comerciais e discursivas das indústrias televisivas que estimulam o envolvimento e o engajamento das audiências em diferentes plataformas, por meio de compartilhamentos de conteúdos gerados pelas emissoras e/ou aplicativos (BORGES et al., 2017; FECHINE et al., 2017 apud BECKER, 2018). 
a essas materialidades, e os valores que lhes são atribuídos pelas culturas profissionais, uma vez que a indústria televisiva e suas produções carregam traços de determinadas organizações e de suas práticas produtivas. Esses estudos combinam análises de práticas culturais com uma abordagem política e econômica das mídias (MENOTTI; CRISP, 2015; MAYER; BANKS; CALDWELL, 2009). É possível inferir que a análise do texto audiovisual sintonizada nas interações das audiências, nas formas de circulação dos conteúdos audiovisuais, nas características da ambiência e nos modos como suas significações também são conformadas nas organizações e práticas produtivas, permite apreender de maneiras mais amplas os atuais processos comunicativos. O esquema analítico da Análise Televisual Convergente auxilia a observação dos regimes de visibilidade do texto e das lógicas de produção, circulação e consumo em um contexto específico. O Gráfico 1, apresentado na próxima seção, oferece uma visualização dessa proposição metodológica, considerando-se a Análise Televisual (BECKER, 2012; 2016) como uma das cinco etapas desse procedimento.

\section{Considerações Finais}

Como uma ferramenta flexível para a análise de telejornais e de programas televisivos, a escolha da aplicação da ATC implica observar: (1) singularidades da ambiência, destacando determinantes tecnológicos e econômicos que a atravessam e experiências de fazer ver e poder agir específicas, e/ou do dispositivo onde um determinado texto está localizado ou ainda os aspectos de um meio que intervêm na forma textual e viabilizam ações interativas; (2) características das organizações e das práticas produtivas, buscando evidenciar as historicidades, os interesses ideológicos, as formas de comercialização e os modelos de negócio de uma emissora de TV, de um canal ou de uma plataforma, bem como atuações e desafios de seus profissionais e/ou colaboradores; (3) os modos como os textos em áudio e vídeo são estruturados, inseridos ou não em uma grade de programação e produzem sentidos e representações, visibilidades e invisibilidades permeados por jogos discursivos em contextos socioculturais e políticos específicos, dimensão esta viabilizada pela aplicação da AT também representada no Gráfico 1, abaixo; (4) as maneiras como um programa ou um conjunto de conteúdos e formatos audiovisuais circulam no ambiente convergente e estabelecem relações com outros produtos televisuais similares; e (5) as interações das audiências, os modos como atribuem significações às narrativas de gêneros televisivos distintos e se sentem motivadas para estabelecer os seus agenciamentos. 


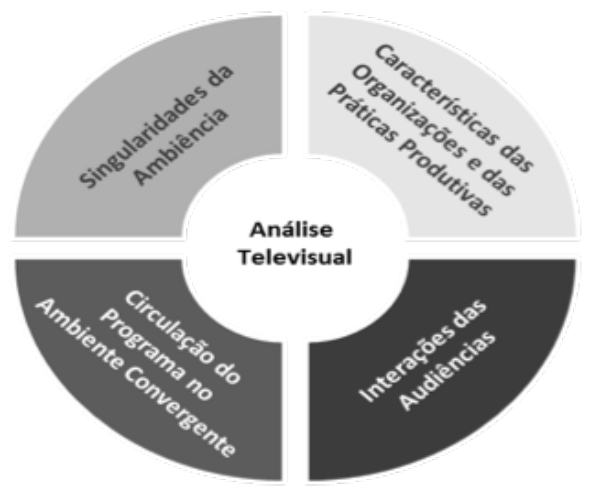

Gráf. 1. Análise Televisual Convergente (ATC).

Fonte: da autora (2018).

A ATC é um instrumento para análises críticas e criativas nas pesquisas em comunicação e em processos formais e informais de aprendizagem dos telejornais e de outros textos audiovisuais televisivos, de suas formas de circulação e das atuações dos sujeitos que produzem, fazem circular e consomem conteúdos e formatos em áudio e vídeo. A aplicação da Análise Televisual Convergente em investigações posteriores poderá sinalizar dinâmicas relevantes para apreensão dos processos comunicativos de noticiários e programas televisivos e lançar luzes sobre a sua operacionalização. Contudo, o principal objetivo deste trabalho teórico-conceitual que parte de um mapeamento empírico é apresentar o esquema analítico da ATC, evidenciando que, ao se tomar os telejornais e os programas televisivos como objetos de estudo, precisa-se reconhecer que estes estão atravessados por diferentes instâncias que complexificam as suas análises, ainda que nem sempre seja possível incorporar todas as dimensões propostas. Sem a pretensão de se sobrepor ou esgotar a diversidade de abordagens dos estudos de televisão e de telejornalismo e aberta ao diálogo com outros procedimentos teórico-metodológicos, a Análise Televisual Convergente busca projetar de maneira sintética um percurso analítico possível que pretende contribuir para outras formas de ver e agir na mídia e no mundo, e colaborar para as suas transformações.

Beatriz Becker é professora associada do Programa de Pós-Graduação em Comunicação e Cultura e do Departamento de Expressão e Linguagens da Escola de Comunicação da Universidade Federal do Rio de Janeiro. É bolsista de Produtividade em Pesquisa do CNPq e líder do Grupo de Pesquisa Mídia, Jornalismo Audiovisual e Educação. É jornalista formada pela ECO-UFRJ, realizou 
Mestrado e Doutorado no PPGCOM-UFRJ e pós-doutorado no Department of Media and Communications da Goldsmiths, University of London, e no Programa de Estudos Pós-Graduados em Comunicação e Semiótica da Pontifícia Universidade Católica de São Paulo (PUC-SP). É autora de Televisão e telejornalismo: transições; A linguagem do telejornal; Pensando e fazendo jornalismo audiovisual e coautora de Pantanal: a reinvenção da telenovela.

beatrizbecker@uol.com.br

\section{Referências}

ALZAMORA G.; ZILLER, J.; D`ANDRÉA, C. Mídia e dispositivos: uma aproximação à luz de Michel Foucault. In: LEAL, B.; CARVALHO, C. A.; ALZAMORA, G.(Org.). Textualidades Midiáticas. Belo Horizonte: PPGCom UFMG, 2018.

BECKER, B. Tendências e desafios da produção noticiosa audiovisual: Contribuições do Grupo de Pesquisa Mídia, Jornalismo Audiovisual e Educação (MJAE) - PPGCOM -UFRJ. In: EMERIN, C.; COUTINHO, I.; FREITAS, C. (Org.). Epistemologias do telejornalismo brasileiro. Florianópolis: Editora Insular, 2018. v. 7, p. $145-172$.

Televisão e Telejornalismo: Transições. São Paulo: Estação das Letras e Cores, 2016.

Mapeamento das pesquisas em Telejornalismo no Brasil: um estudo da produção acadêmicocientífica de 2010 a 2014. Revista FAMECOS: mídia, cultura e tecnologia, v. 22, n. 4, 2015. PPGCS-PUC-RS, Porto Alegre, 2015. Disponível em: <http://revistaseletronicas.pucrs.br/ojs/index.php/ revistafamecos/article/view/20534>. Acesso em: 23 out. 2018.

. Mídia e Jornalismo como formas de conhecimento: uma metodologia para leitura crítica das narrativas jornalísticas audiovisuais. Matrizes, Revista do PPG em Ciências da Comunicação da USP, São Paulo, v. 5, n. 2, p. 231-250, 2012. Doi: <http://dx.doi.org/10.11606/issn.1982-8160.v5i2p231-250>.

BELTRÁN, M. Representation. In: Kackman, M.; KEARNEY, M. C. (Org.). The Craft of Criticism. Critical Media Studies in Practice. New York: Routledge, 2018. p. 97-108.

BRAGA, J. L. Circuitos da Comunicação. In: BRAGA, José Luiz; CALAZANS, Regina (Org.). Matrizes Interacionais. A Comunicação Constrói a Sociedade. Campina Grande: Eduepb (Editora da Universidade Federal da Paraỉba), 2017. p. 43-64.

EMERIN, C.; COUTINHO, I.; FINGER, C. Epistemologias do telejornalismo brasileiro. Florianópolis: Insular, 2018.

FAUSTO NETO, A. Indo Além do "Leitor-Modelo". In: FIGARO, Roseli; BRIGNOL, Liliane Dutra (Org.). Trabalho do Pesquisador: Os Desafios à Empiria em Estudos de Recepção. Curitiba: Appris, 2017. p. 257-279.

FECHINE, Y. Transmidiação como modelo de produção: uma abordagem a partir de estudos de televisão e linguagem. In: MASSAROLO, J.; SANTAELLA, L.; NESTERIUK, S. (Org.). Desafios da Transmídia: Processos e Poéticas. São Paulo: Estação das Letras e Cores, 2018. p. 42-63.

GUIMARÃES, C. O Novo Regime do Visível e As Imagens Digitais. In: VAZ, Paulo B.; CASA NOVA, Vera (Org.). Estação Imagem. Belo Horizonte: Ed. UFMG, 2002.

HALL, S. Cultura e Representação. Rio de Janeiro: Ed. PUC Rio; Apicuri, 2016. 
HILLS, M. Audiences. In: KACKMAN, M.; KEARNEY, M. C. (Org.). The Craft of Criticism. Critical Media Studies in Practice. New York: Routledge, 2018. p. 183- 194.

LEAL, B. Do texto à textualidade na comunicação: contornos de uma linha de investigação. In: LEAL, B.; CARVALHO, C. A.; ALZAMORA, G. (Org.). Textualidades Midiáticas. Belo Horizonte: PPGCom UFMG, 2018. p. 17-34.

MACHADO, A. A televisão levada a sério. São Paulo: Senac, 2003.

MARINHO, S. MARIÑO, M. V. Uma Paisagem da Epistemologia e Metodologia em Comunicação. Comunicação e Sociedade, v. 33, p. 7-14, 2018.

MARTINO, L. M. S. Métodos de Pesquisa em Comunicação. Petrópolis: Vozes, 2018.

MAYER, V.; BANKS, M. J.; CALDWELL, J. T. (Org.). Production Studies: Cultural Studies of Media Insdustries. Nova lorque: Routledge, 2009.

MENOTTI, G.; CRISP, V. Besides the Screen: moving images through distribution, promotion and curation. Londres; Nova lorque: Palgrave Macmillan, 2015.

MINAYO, M. C. S. O Desafio do Conhecimento. São Paulo: HUCITEC, 2014.

MITCHELL, W. J. T. O que as imagens realmente querem? In: ALLOA, Emmanuel (Org.). Pensar a Imagem. Belo Horizonte: Autêntica Editora, 2017.

MITTELL, J. Genre and Television. From cop shows to cartoons in American Culture. Nova lorque; Londres: Routledge, 2004.

RANCIÈRE, J. O destino das imagens. Rio de Janeiro: Contraponto Editora, Ltda., 2016.

O Espectador Emancipado. São Paulo: Martins Fontes, 2017.

ROCHA, S. M. Análise do estilo: um percurso metodológico. In: ROCHA, Simone Maria (Org.). Estilo Televisivo e a sua pertinência para a TV como prática cultural. Florianópolis: Editora Insular, 2016.

SANTAELLA, L.; NÖTH, W. Imagem: cognição, semiótica, mídia. São Paulo: Iluminuras, 2008.

SODRÉ, M. A Ciência do Comum. Notas para o método comunicacional. Petrópolis: Vozes, 2014.

WILLIAMS, R. Televisão, tecnologia e forma cultural. São Paulo: Boitempo; Belo Horizonte: PUCMinas, 2016. 